\title{
Lungs Complete Response GvHD
}

National Cancer Institute

\section{Source}

National Cancer Institute. Lungs Complete Response GVHD. NCI Thesaurus. Code

C126707.

Either normal \%FEV1, alkaline phosphatase, and total bilirubin after previous elevation of 1 or more or an NIH lung symptom score of 0 following GVHD involvement. 